\title{
PEMBERIAN PUDING TOMAT PISANG AMBON TERHADAP PENURUNAN TEKANAN DARAH LANSIA HIPERTENSI DI POSBINDU WILAYAH KERJA PUSKESMAS BABAKAN, KOTA MATARAM
}

\author{
Mutammi Widya Desira ${ }^{1 *}$, Ni Ketut Sri Sulendri ${ }^{1}$, Fifi Luthfiyah $^{1}{ }^{1}$ an Suhaema ${ }^{1}$ \\ Jurusan Gizi, Poltekkes Kemenkes Mataram, Indonesia Jl. \\ Praburangkasari Dasan Cermen, Sandubaya Kota Mataram \\ Email : desirawidya@gmail.com
}

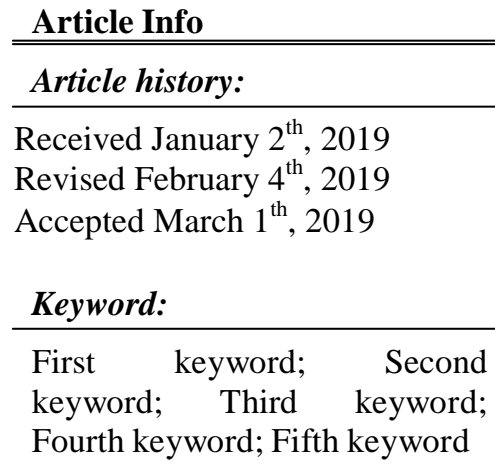

ABSTRACT (10 PT)

Background: hypertension or high blood pressure is an increase in one's blood pressure, wherein systolic blood pressure $\geq 140 \mathrm{mmHg}$ and or diastolic blood pressure $\geq 90 \mathrm{mmHg}$ on repeated examinations. Hypertension often occurs in the elderly caused by changes occurring during the aging process that cause the walls of blood vessels to undergo thickening and hardening so that it becomes stiff, the diameter of the cavity of the blood vessels shrink or Narrows. One form of non-pharmacological treatment in overcoming hypertension is by herbal medicine, namely by utilizing the content of potassium in fruits and vegetables, such as bananas and tomatoes containing high potassium that can decrease blood pressure, especially in elderly groups.

Research Methods: Type of Quasy-experimental research with PretestPosttest with Control Group Draft. The samples in this study were elderly hypertension as many as 18 people with random techniques divided into 2 groups. Group intervention with the giving of tomato banana pudding ambon as much as 175 gram/day for 6 days, while the control group is not given treatment.

Research Result: There is a decrease in systolic blood pressure as much as $17.8 \mathrm{mmHg}(\mathrm{P}=0,002)$ and diastolic blood pressure as much as $8.9 \mathrm{mmHg}$ $(\mathrm{P}=0,347)$ in the intervention group.

Conclusio: There is an influence on the systolic blood pressure but there is no influence on diastolic blood pressure before and after given banana tomato pudding Ambon.

Keywords: tomato pudding and ambon banana, hypertension, elderly person.

Copyright () JurnalGizi Prima All rights reserved.

\begin{abstract}
PENDAHULUAN
Hipertensi adalah keadaan meningkatnya tekanan darah seseorang, dimana tekanan darah sistolik $\geq 140$ $\mathrm{mmHg}$ dan atau tekanan darah diastolik $\geq 90 \mathrm{mmHg}$ pada pemeriksaan yang berulang (Perhimpunan Dokter Spesialis Kardiovaskular Indonesia [PERKI], 2015). Hipertensi juga sering disebut sebagai silent killer karena termasuk penyakit yang mematikan. Hipertensi tidak dapat secara langsung membunuh penderitanya, melainkan hipertensi memicu terjadinya penyakit lain serta dapat meningkatkan resiko serangan jantung, gagal jantung, stroke dan gagal ginjal (Pudiastuti, 2013 dalam Seke, dkk. 2016).
\end{abstract}

Data WHO tahun 2000 menunjukkan, di seluruh dunia sekitar 972 juta orang atau 26,4\% penduduk dunia mengidap hipertensi. Angka ini kemungkinan akan meningkat menjadi 29,2\% di 
tahun 2025. Dari 972 juta pengidap hipertensi, 333 juta berada di negara maju dan 639 sisanya berada di negara sedang berkembang, termasuk Indonesia (Suhadak, dkk. 2011).

Menurut Riset Kesehatan Dasar (Riskesdas) tahun 2013 diketahui prevalensi hipertensi di Indonesia pada responden yang berumur 18 tahun ke atas, ditemukan sebesar 25,8\%. Prevalensi hipertensi yang tertinggi terdapat di Bangka Belitung (30,9\%), sedangkan prevalensi hipertensi di Nusa Tenggara Barat adalah 24,3\% yang merupakan urutan ke 17 dari seluruh provinsi di Indonesia.

Prevalensi hipertensi pada lansia dengan usia 65-74 tahun mencapai 65\%, sedangkan $80 \%$ terjadi pada lansia dengan usia 75 tahun keatas. Lansia sering terkena hipertensi karena dinding pembuluh darah mengalami penebalan dan pengerasan sehingga menjadi kaku, diameter rongga pembuluh darah mengecil atau menyempit sehingga aliran darah tidak selancar pada usia muda, hal ini menyebabkan elastisitas (kelenturan) pembuluh darah berkurang. Penebalan dan pengerasan dinding pembuluh darah ini terjadi karena penimbunan jaringan ikat, kalsifikasi dan penimbunan lemak (Jain, 2011 dalam Alini, 2015).

Hipertensi dapat dikendalikan dengan pengobatan farmakologi dan non-farmakologi. Pengobatan farmakologi merupakan pengobatan menggunakan obat anti hipertensi untuk menurunkan tekanan darah (Marliani \& Tantan, 2007 dalam Fahriza, dkk. 2014). Pengobatan non farmakologi merupakan pengobatan tanpa obatobatan, dengan merubah gaya hidup menjadi lebih sehat dan menghindari faktor-faktor yang dapat berisiko. Salah satu bentuk pengobatan non farmakologi dalam mengatasi hipertensi adalah dengan pengobatan herbal yaitu dengan memanfaatkan kandungan kalium pada buah dan sayuran (Fahriza, dkk. 2014). Konsumsi kalium yang banyak akan meningkatkan konsentrasinya didalam cairan intraseluler sehingga cenderung menarik cairan dari bagian ekstraseluler dan menurunkan tekanan darah (Astawan, 2002, dalam Imammudin, 2016). Salah satu buah yang mengandung kalium tinggi adalah pisang ambon yang bekerja mirip obat antihipertensi di dalam tubuh manusia sehingga dapat menurunkan tekanan darah. Sayuran lain yang mengandung kalium adalah tomat (Lycopersicum commune), selain mengandung kalium tomat juga mengandung likopen yang mempunyai efek menurunkan tekanan darah (Rini, 2016). Selain zat gizi kalium, kandungan yang berperan adalah serat. Serat merupakan jenis karbohidrat yang tidak terlarut. Serat berkaitan dengan pencegahan terjadinya tekanan darah tinggi terutama jenis serat kasar (crude fiber) seperti agar-agar dan rumput laut. Salah satu bentuk olahan dari rumput laut yang diekstrak menjadi agar-agar (karaginan) adalah puding yang merupakan salah satu makanan penutup atau disebut juga sebagai makanan pencuci mulut (Nurjanah, dkk. 2007).

Berdasarkan latar masalah diatas, maka penulis termotivasi untuk meneliti tentang pengaruh pemberian puding tomat pisang ambon terhadap penurunan tekanan darah lansia hipertensi di posbindu wilayah kerja puskesmas Babakan kota Mataram.

\section{METODE PENELITIAN}

Jenis penelitian ini adalah Quasy-eksperimental dengan rancangan (Pretest-Posttest with Control Group). Dalam rancangan ini, pengelompokan anggota sampel pada kelompok eksperimen dan kelompok kontrol dilakukan secara random atau acak. Teknik pengambilan sampel pada penelitian ini melalui randomisasi sederhana (Simple Random Sampling) yaitu menggunakan teknik undian. Sampel dalam penelitian ini berjumlah 18 orang. Analisa yang digunakan adalah analisa univariat dan analisa bivariat. Analisis bivariat menggunakan uji Mann-Whitney yaitu uji dua mean dependen dengan tingkat kepercayaan 95\% dan tingkat kemaknaan $\mathrm{p}$ value $<0,05$. Analisa data menggunakan bantuan program komputerisasi. 
JurnalGizi Prima

Vol.4, Edisi.1, Maret 2019, pp. 31 39

ISSN: 2656 - 2480 (Online)

ISSN: 2355 - 1364 (Print)

\section{HASIL PENELITIAN}

Karakteristik Sampel

Tabel 1. Distribusi Karakteristik Sampel Menurut Usia, Jenis Kelamin, Status Gizi, Riwayat Hipertensi Pada Keluarga/Genetik, Kebiasaan Merokok, Konsumsi Minuman Alkohol dan Konsumsi Obat-obatan Anti Hipertensi.

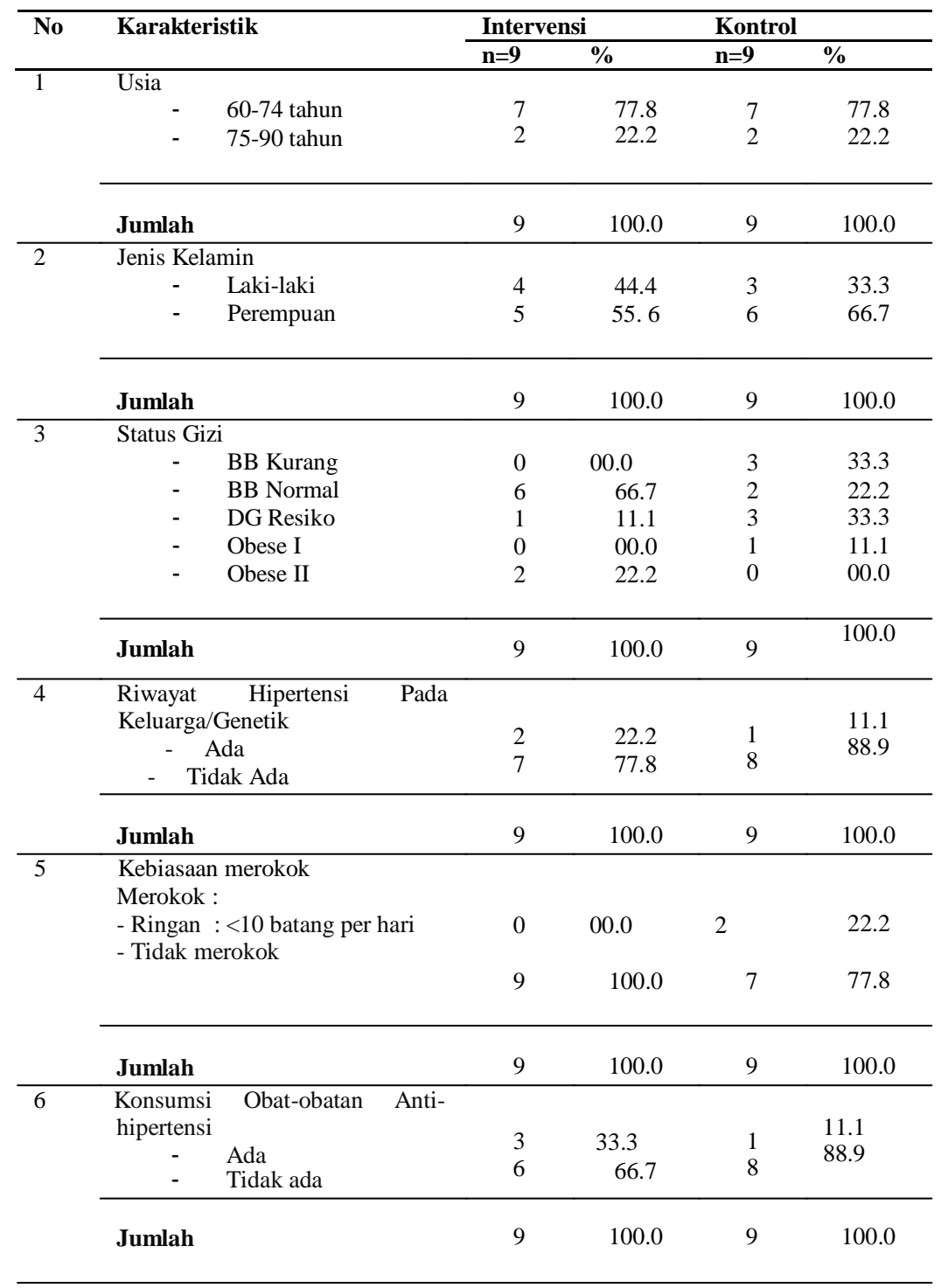

Berdasarkan tabel 1, dapat diketahui bahwa karakteristik sampel menurut usia sebagian besar sampel pada kelompok intervensi maupun kelompok kontrol berusia 60-74 tahun, yaitu terdapat 7 sampel (77.8\%). Pada karakteristik sampel menurut jenis kelamin dapat diketahui bahwa sebagian besar sampel dari kedua kelompok berjenis kelamin perempuan, yaitu terdapat 5 sampel $(55.6 \%)$ pada kelompok intervensi dan 6 sampel (66.7\%) pada kelompok kontrol. Pada karakteristik status gizi sampel dapat diketahui bahwa sebagian besar sampel pada kelompok intervensi memiliki status gizi normal yaitu 6 sampel (66.7\%) dan 4 sampel (44.4\%) memiliki status gizi dengan resiko. Pada karakteristik sampel menurut riwayat hipertensi pada keluarga/genetik dapat diketahui bahwa sebagian besar pada kedua kelompok sampel tidak memiliki riwayat hipertensi pada keluarga/genetik, yaitu 7 sampel (77.8\%) pada kelompok intervensi dan 8 sampel (88.9\%) pada

kelompok kontrol. Pada karakteristik sampel menurut kebiasaan merokok dapat diketahui bahwa sebagian besar sampel pada kedua kelompok tidak memiliki kebiasaan merokok, yaitu 9 sampel $(100.0 \%)$ pada kelompok intervensi dan 7 sampel (77.8\%) pada kelompok kontrol. Pada data karakteristik sampel 


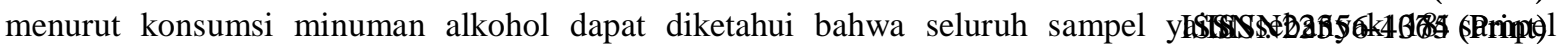
$(100.0 \%)$ pada kelompok intervensi maupun kelompok kontrol tidak mengkonsumsi minuman alkohol. Pada karakteristik sampel menurut konsumsi obat-obatan antihipertensi dapat diketahui bahwa sebagian besar sampel dari kedua kelompok tidak mengkonsumsi obat-obatan antihipertensi, yaitu 6 sampel (66.7\%) pada kelompok intervensi dan 8 sampel (88.9\%) pada kelompok kontrol.

\section{Tingkat Konsumsi Zat Gizi}

\section{Asupan Kalium Sebelum dan Selama Intervensi}

Tingkat Asupan Kalium Sebelum Intervensi

Tingkat asupan kalium sampel sebelum intervensi termasuk dalam kategori tingkat asupan defisit berat yaitu sebanyak 9 sampel (100.0\%) pada kelompok intervensi dengan rata-rata asupan sebesar 1051,1 mg atau 22\% dari kebutuhan dan 9 sampel (100.0\%) pada pada kelompok kontrol dengan rata-rata asupan 1454,6 mg atau $31 \%$ dari kebutuhan.

\section{Tingkat Asupan Kalium Selama Intervensi}

Tingkat asupan kalium sampel selama intervensi termasuk dalam kategori tingkat asupan defisit berat yaitu sebanyak 9 sampel (100.0\%) pada kelompok intervensi dengan rata-rata asupan sebesar 2199,8 mg atau $47 \%$ dari kebutuhan dan 9 sampel (100.0\%) pada kelompok kontrol dengan rata-rata asupan sebesar 1161,0 mg atau $25 \%$ dari kebutuhan

\section{Asupan Natrium Sebelum dan Selama Intervensi}

Tingkat Asupan Natrium Sebelum Intervensi

Tingkat asupan natrium sampel sebelum intervensi termasuk dalam kategori normal sebanyak 9 sampel (100.0\%) pada kelompok intervensi dengan rata-rata asupan sebesar 835,8 mg atau 36\% dari kebutuhan dan 9 sampel (100.0\%) pada pada kelompok kontrol dengan rata-rata asupan 836,6 mg atau 36\% dari kebutuhan.

\section{Tingkat Asupan Natrium Selama Intervensi}

Tingkat asupan natrium selama intervensi termasuk dalam kategori normal sebanyak 9 sampel (100.0\%) pada kelompok intervensi dengan rata-rata asupan sebesar 934,5 mg atau 41\% dari kebutuhan dan 9 sampel (100.0\%) pada pada kelompok kontrol dengan rata-rata asupan 931,9 mg atau 40\% dari kebutuhan.

\section{Asupan Serat Sebelum dan Selama Intervensi Tingkat Asupan Serat Sebelum Intervensi}

\begin{tabular}{|l|c|c|c|c|}
\hline \multirow{2}{*}{$\begin{array}{c}\text { Klasifikasi Tingkat } \\
\text { Asupan Zat Gizi }\end{array}$} & \multicolumn{2}{|c|}{ Intervensi } & \multicolumn{2}{c|}{ Kontrol } \\
\cline { 2 - 5 } & $\mathrm{n}-9$ & $\%$ & $\mathrm{n}-9$ & 11.1 \\
\hline Di atas kecukupan & 2 & 22.2 & 4 & 44.4 \\
\hline Normal & 3 & 33.3 & 0 & 00.0 \\
\hline Defisit tingkat ringan & 1 & 11.1 & 0 & 00.0 \\
\hline Defisit tingan sedang & 3 & 33.3 & 4 & 44.4 \\
\hline Defisit tingan berat & 0 & 00.0 & 9 & 100.0 \\
\hline Jumlah & 9 & 100.0 & & \\
\hline
\end{tabular}

Berdasarkan tabel 2, dapat diketahui bahwa tingkat asupan serat sampel sebelum intervensi termasuk dalam kategori tingkat asupan diatas kebutuhan sebanyak 2 sampel (22.2\%), tingkat asupan normal sebanyak 3 sampel (33.3\%), defisit tingkat ringan sebanyak 1 sampel (11.1\%) dan defisit tingkat sedang sebanyak 1 sampel $(11.1 \%)$ dengan rata-rata asupan sebesar 27,6 gram atau 
98\% dari kebutuhan. Sedangkan pada kelompok kontrol, terdapat 1 sampel (11.1\%) termasuk dalam kategori tingkat asupan diatas kebutuhan, 4 sampel (44.4\%) termasuk dalam kategori asupan normal, dan 4 sampel $(44.4 \%)$ termasuk dalam kategori tingkat asupan defisit tingkat berat dengan rata-rata asupan sebesar 25,4 gram atau $92 \%$ dari kebutuhan.

\section{Tingkat Asupan Serat Selama Intervensi}

\begin{tabular}{|l|c|c|c|c|}
\hline \multicolumn{1}{|c|}{$\begin{array}{c}\text { Klasifikasi Tingkat } \\
\text { Asupan Zat Gizi }\end{array}$} & \multicolumn{2}{|c|}{ Intervensi } & \multicolumn{2}{c|}{ Kontrol } \\
\cline { 2 - 5 } & $\mathrm{n}-9$ & $\%$ & $\mathrm{n}-9$ & 11.1 \\
\hline Di atas kecukupan & 1 & 11.1 & 3 & 33.3 \\
\hline Normal & 6 & 66.7 & 0 & 00.0 \\
\hline Defisit tingkat ringan & 1 & 00.0 & 1 & 11.1 \\
\hline Defisit tingan sedang & 1 & 11.1 & 4 & 44.4 \\
\hline Defisit tingan berat & 0 & 00.0 & 9 & 100 \\
\hline Jumlah & 9 & 100.0 & & \\
\hline
\end{tabular}

Berdasarkan tabel 3, dapat diketahui bahwa tingkat asupan serat sampel selama intervensi termasuk dalam kategori tingkat asupan diatas kebutuhan sebanyak 1 sampel (11.1\%), tingkat asupan normal sebanyak 6 sampel (66.7\%), tingkat asupan defisit tingkat ringan sebanyak 1 sampel (11.1\%) dan tingkat asupan defisit tingkat sedang sebanyak 1 sampel (11.1\%) pada kelompok intervensi dengan rata-rata asupan sebesar 27,8 gram atau $103 \%$ dari kebutuhan. Sedangkan pada kelompok kontrol, terdapat 1 sampel (11.1\%) termasuk dalam kategori tingkat asupan diatas kebutuhan, 3 sampel (33.3\%) termasuk dalam kategori normal, 1 sampel (11.1\%) termasuk dalam kategori defisit tingkat sedang dan 4 sampel (44.4\%) termasuk dalam kategori defisit tingkat berat dengan rata-rata asupan sebesar 25,7 gram atau $96 \%$ dari kebutuhan.

Tekanan Darah

Analisis Pengaruh Pemberian Puding Tomat Pisang Ambon Terhadap Penurunan Tekanan Darah Pada Sampel Penelitian

Tabel 4. Analisis Pengaruh Pemberian Puding Tomat Pisang Ambon Terhadap Penurunan Tekanan Darah Pada Sampel Penelitian

\begin{tabular}{|c|l|c|c|c|c|}
\hline \multirow{2}{*}{ No } & \multicolumn{1}{|c|}{ Keterangan } & Sistolik & & Diatolik & \\
\cline { 3 - 6 } & & Intervensi & Kontrol & Intervensi & Kontrol \\
\hline 1 & Tekanan Darah & 17.8 & -1.1 & 8.9 & 4.4 \\
\hline 2 & SD & 3.39 & 2.84 & 3.10 & 2.51 \\
\hline 3 & Sig. & \multicolumn{2}{|c|}{0.002} \\
\hline
\end{tabular}

Ket : $\Delta \quad$ : Rata-rata perubahan tekanan darah

Sig. :Nilai Mann Whitney pada $\alpha=0.05$

Berdasarkan tabel 4, dapat diketahui bahwa dengan menggunakan uji statistik Mann Whitney pada $\alpha=$ 0.05, didapatkan hasil selisih perubahan tekanan darah antara kelompok intervensi dan kelompok kontrol pada tekanan darah sistolik yaitu dengan nilai $\mathrm{p}=0.002(\mathrm{p}<0.05)$ dan untuk tekanan darah diastolik dengan nilai $\mathrm{p}=0.347 \quad(\mathrm{p}>0.05)$. Hal tersebut menunjukkan bahwa terdapat perbedaan yang signifikan pada perubahan tekanan darah sistolik antara kelompok intervensi dan kelompok kontrol, sedangkan pada tekanan darah diastolik tidak terdapat perbedaan yang signifikan pada kelompok intervensi dan kelompok kontrol. Rata-rata perubahan tekanan darah pada kelompok intervensi yaitu tekanan darah sistolik menurun sebesar 17,8 $\mathrm{mmHg}$ dan tekanan darah diastolik menurun sebesar $8,9 \mathrm{mmHg}$. Sedangkan pada kelompok kontrol, rata-rata perubahan tekanan darah sistolik yaitu meningkat sebesar $-1,1 \mathrm{mmHg}$ dan tekanan darah diastolik menurun sebesar $4,4 \mathrm{mmHg}$.

\section{PEMBAHASAN}

\section{Karakteristik Sampel}

Karakteristik Sampel Berdasarkan Usia

Karakteristik sampel berdasarkan usia menunjukkan bahwa sebagian besar sampel yaitu sebanyak 7 orang (77.8\%) baik pada kelompok intervensi maupun kontrol berusia 60-74 tahun. Hal ini sesuai dengan hasil penelitian Mega dkk (2010) dalam Lara (2013) yang menunjukkan sebagian besar sampel pada penelitian tersebut berada pada usia di atas 40 tahun. Pertambahan usia menyebabkan semakin meningkatnya tekanan darah seseorang dikarenakan dinding pembuluh darah mengalami penebalan dan pengerasan sehingga menjadi 
kaku, diameter rongga pembuluh darah mengecil atau menyempit sehingga elastisitas pembuluh darah berkurang (Wiryowidagdo dan Sitanggang 2002 dalam Alini, 2015). Hasil penelitian yang dilakukan Sigarlaki (2006) dalam Alini (2015) menyatakan bahwa terdapat hubungan antara usia dengan tekanan darah tinggi.

Hasil penelitian lain oleh Budi dkk (2011) dalam Novitaningtyas (2014), menyatakan bahwa terdapat hubungan yang bermakna antara umur lansia (60-90 tahun) dengan tekanan darah.

\section{Karakteristik Sampel Berdasarkan Jenis Kelamin}

Berdasarkan karakteristik sampel mengenai jenis kelamin menunjukkan bahwa sebagian besar sampel memiliki jenis kelamin perempuan yaitu sebanyak 5 orang (55.6\%) pada kelompok intervensi dan 6 orang $(66.7 \%)$ pada kelompok kontrol. Salah satu faktor yang mempengaruhi tekanan darah adalah jenis kelamin, karena berpengaruh terhadap kadar hormon yang dimiliki seseorang (Hananta dan Freltag, 2011). Penelitian yang dilakukan oleh Irza (2009) di Nagari Bungo Tanjung Sumatra Barat, menyebutkan bahwa prevalensi hipertensi pada perempuan lebih besar daripada laki-laki, dengan persentase $66,67 \%$ pada perempuan dan $33,33 \%$ pada laki-laki. Hasil penelitian Syukraini (2009) dalam Mustika Lara (2013) menyatakan bahwa terdapat hubungan yang signifikan antara umur dengan kejadian hipertensi.

\section{Karakteristik Sampel Berdasarkan Status Gizi}

Berdasarkan karakteristik sampel mengenai status gizi menunjukkan bahwa sampel memiliki status gizi obese sebanyak 3 orang (33.3\%) pada kelompok intervensi dan dengan resiko obese sebanyak 4 orang (44.4\%) pada kelompok kontrol. Hasil penelitian ini sejalan dengan yang dilakukan oleh Handayani dan Sartika (2013), dimana terdapat hubungan yang signifikan antara indeks massa tubuh dengan hipertensi. Dalam penelitian ini juga menunjukkan sampel sebagian besar memiliki status gizi normal. Menurut Admin (2008) dalam Raihan, dkk (2014) orang yang tidak obesitas bukan berarti tidak bisa terkena hipertensi karena hipertensi memiliki banyak faktor risiko seperti usia, jenis kelamin, asupan kalium, kebiasaan berolahraga dan stress. Akan tetapi apabila orang tersebut mengalami obesitas, maka risiko untuk mengalami hipertensi juga meningkat.

\section{Karakteristik Sampel Berdasarkan Riwayat Hipertensi pada Keluarga/Genetik}

Berdasarkan karakteristik sampel mengenai ada atau tidak adanya riwayat hipertensi pada keluarga menunjukkan bahwa sebagian besar sampel yaitu 7 orang $(77.8 \%)$ pada kelompok intervensi dan 8 orang (88.9\%) pada kelompok kontrol tidak memiliki riwayat hipertensi pada keluarga/genetik. Hal ini sejalan dengan penelitian yang dilakukan oleh Adiningsih (2012) dalam Mahmudah, dkk (2015) yang menunjukkan bahwa tidak ada hubungan yang bermakna antara keturunan dengan hipertensi, karena dapat juga disebabkan oleh gaya hidup yang tidak sehat seperti aktivitas fisik dan stres. Hal ini dibuktikan oleh penelitian yang dilakukan Muliyati, dkk (2011) menunjukkan bahwa ada hubungan antara aktivitas fisik dengan kejadian hipertensi, sebanyak64,4\% sampel memiliki aktivitas fisik ringan menderita hipertensi, sedangkan $100.0 \%$ sampel yang beraktivitas fisik sedang tidak hipertensi. Dan hasil penelitian oleh Sount, dkk (2014) yang menunjukkan bahwa ada hubungan yang bermakna antara stress dengan kejadian hipertensi di Puskesmas Kolongan Kecamatan Kalawat.

\section{Karakteristik Sampel Berdasarkan Kebiasaan Merokok}

Berdasarkan hasil penelitian menunjukkan bahwa sebagian besar sampel tidak memiliki kebiasaan merokok yaitu sebanyak 9 sampel (100\%) pada kelompok intervensi dan 7 sampel (77.8\%) pada kelompok kontrol. Hal ini berbeda dengan hasil penelitian yang dilakukan oleh Anggara dan Prayitno (2012) bahwa terdapat hubungan yang signifikan antara kebiasaan merokok dengan status tekanan darah.

\section{Karakteristik Sampel Berdasarkan Konsumsi Minuman Alkohol}

Berdasarkan hasil penelitian menunjukkan bahwa seluruh sampel sebanyak 18 sampel (100\%) tidak mengkonsumsi minuman alkohol. Hal ini sesuai dengan penelitian Arifin, dkk (2016) yang menyatakan bahwa sebagian besar lansia (89.3\%) tidak mengkonsumsi alkohol. Hasil penelitian lain oleh Raihan, dkk (2014) juga mengatakan tidak ada hubungan yang bermakna secara statistik antara konsumsi alkohol dengan penyebab hipertensi primer. Namun hasil penelitian ini berbeda dengan penelitian yang dilakukan Anggara dan Prayitno (2012) yang mengatakan bahwa terdapat hubungan antara konsumsi alkohol dengan status tekanan darah.

\section{Karakteristik Sampel Berdasarkan Konsumsi Obat-obatan Anti-hipertensi}

Berdasarkan hasil penelitian menunjukkan bahwa sebagian besar sampel tidak mengkonsumsi obat-obatan antihipertensi yaitu sebanyak 6 sampel (66.7\%) pada kelompok intervensi dan 8 sampel (88.9\%) pada kelompok kontrol. Hal ini karena obat-obatan anti-hipertensi yang biasa di konsumsi habis. Sampel yang 
mengkonsumsi obat-obatan antihipertensi pada saat intervensi hanya 4 sampel yaitu 3 sampel (33.3\%) pada kelompok intervensi dan 1 sampel (11.1\%) pada kelompok kontrol. Penggunaan obat antihipertensi yang digunakan oleh sampel adalah Amlodipin, dikonsumsi 1-2x sehari secara oral.

\author{
Asupan Zat Gizi \\ Asupan Kalium \\ Asupan zat gizi yang dilihat dari penelitian ini adalah asupan kalium dan natrium, dimana kedua zat gizi \\ tersebut memiliki kaitan yang erat dengan hipertensi. Kalium dan natrium adalah pasangan mineral yang bekerja \\ sama dalam memelihara keseimbangan cairan, elektrolit, dan asam basa sehingga dua
}

mineral tersebut berpengaruh terhadap regulasi tekanan darah. Pengaruh kalium dalam tekanan darah terjadi jika natrium di dalam tubuh juga tinggi, tetapi jika asupan natrium normal atau kurang maka pengaruh tersebut tidak akan terlihat (Hasna, 2014 dalam Susanti, 2017).

Asupan kalium berhubungan lebih dengan penurunan tekanan darah. Kalium berpartisipasi dalam memelihara keseimbangan cairan, elektrolit dan asam basa. Mekanisme bagaimana kalium dapat menurunkan tekanan darah adalah kalium dapat menurunkan tekanan darah dengan vasodilatasi sehingga menyebabkan penurunan retensi perifer total dan meningkatkan output jantung, kalium dapat menurunkan tekanan darah dengan berkhasiat sebagai diuretika, kalium dapat mengubah aktivitas sistem renin-angiotensin, kalium dapat mengatur saraf perifer dan sentral yang mempengaruhi tekanan darah. Kalium merupakan ion utama didalam cairan intraseluler. Konsumsi kalium yang banyak akan meningkatkan konsentrasinya didalam cairan intraseluler sehingga cenderung menarik cairan dari bagian ekstraseluler dan menurunkan tekanan darah (Astawan, 2002 dalam Imammudin, 2016). Hasil penelitian ini juga sejalan dengan penelitian yang dilakukan oleh Riyadi dkk (2007) membuktikan bahwa asupan kalium mempengaruhi kadar tekanan darah.

\title{
Asupan Natrium
}

Asupan natrium yang meningkat menyebabkan tubuh meretensi cairan, yang meningkatkan volume darah. Jantung harus memompa keras untuk mendorong volume darah yang meningkat melalui ruang yang semakin sempit yang akibatnya adalah hipertensi (Mulyati, dkk. 2011). Hal ini dibuktikan dalam penelitian yang dilakukan oleh Abdurrachim, dkk (2016) bahwa ada hubungan yang bermakna antara asupan natrium terhadap tekanan darah lansia di Panti Sosial Tresna Werdha dan Bina Laras Budi Luhur Kota Banjarbaru. Penelitian tersebut menunjukkan adanya korelasi positif yang bermakna antara asupan natrium terhadap tekanan darah sistol dan diastol. Korelasi positif dapat diartikan bahwa makin tinggi asupan natrium, maka tekanan darah sistolik dan diastolik akan semakin meningkat. Hasil penelitian ini juga sejalan dengan penelitian Arlita (2014) menunjukkan bahwa adanya hubungan antara asupan natrium dengan tekanan darah.

\section{Asupan Serat}

Penelitian Sari, dkk (2016) mengatakan bahwa pada penderita hipertensi, pemberian diet tinggi serat sangat penting. Mekanisme serat untuk menurunkan tekanan darah berkaitan dengan asam empedu. Serat pangan mampu mengurangi kadar kolesterol yang bersirkulasi dalam plasma darah dengan cara mengikat garam empedu, mencegah penyerapan kolesterol didalam usus dan meningkatkan pengeluaran asam empedu lewat feses yang dapat meningkatkan konversi kolesterol plasma menjadi asam empedu dan mengakibatkkan menurunnya tekanan darah (Lestari, dkk. 2012 dalam Kholifah, dkk. 2014). Intake serat yang rendah dapat menurunkan eksresi lemak dan asamempedu melalui feses dan diabsorpsi kembali kealiran darah. Akibatnya kolesterol yang beredar dalam darah semakin banyak dan menumpuk di pembuluh darah dan menghambat aliran darah. Hal ini berdampak pada peningkatan tekanan darah.

\section{Pengaruh Pemberian Puding Tomat Pisang Ambon Terhadap Penurunan Tekanan Darah Lansia Hipertensi di Posbindu wilayah kerja Puskesmas Babakan, Kota Mataram}

Puding tomat pisang ambon merupakan puding kombinasi dari 150 gram tomat buah dan 100 gram pisang ambon yang diberikan setiap hari selama 6 hari dengan kandungan kalium yang cukup tinggi yaitu 667,35 mg dalam \pm 175 gr puding.Pengaruh pemberian puding tomat pisang ambon terhadap penurunan tekanan darah

sistolik dan diastolik dapat diketahui dengan melihat nilai p-value menggunakan uji Mann-Whitney Test yang menunjukkan bahwa hasil tekanan darah sistolik pada kelompok intervensi dan kelompok kontrol dengan nilai $\mathrm{p}=0,002$, yang artinya terdapat perbedaan terhadap penurunan tekanan darah sistolik dengan $\Delta$ perubahan tekanan darah sistolik pada kelompok intervensi menurun sebesar 17,8 $\mathrm{mmHg}$, sedangkan pada kelompok kontrol meningkat sebesar $1,1 \mathrm{mmHg}$. Hasil tekanan darah diastolik pada kelompok intervensi maupun 
kelompok kontrol dengan nilai $\mathrm{p}=0,347$, yang artinya tidak terdapat perbedaan terhadap penurunan tekanan darah diastolik dengan $\Delta$ perubahan tekanan darah diastolik pada kelompok intervensi menurun sebesar 8,9 $\mathrm{mmHg}$ dan pada kelompok kontrol menurun sebesar $4,4 \mathrm{mmHg}$. Konsumsi kalium yang banyak akan meningkatkan konsentrasinya didalam cairan intraseluler sehingga cenderung menarik cairan dari bagian ekstraseluler dan menurunkan tekanan darah (Astawan, 2002, dalam Imammudin, 2016). Hasil penelitian yang dilakukan Alini (2015) menunjukkan adanya penurunan tekanan darah sistolik sebesar 13,86 $\mathrm{mmHg}$ dan tekanan darah diastolik sebesar $10 \mathrm{mmHg}$ pada lansia penderita hipertensi yang diberikan pisang ambon sebanyak 3 buah $( \pm 140 \mathrm{~g} / \mathrm{buah})$ perhari selama 7 hari. Penelitian Kurniasari (2012) didapatkan hasil bahwa terjadi penurunan tekanan darah sistolik dan diastolik pada lansia dengan diberikan 100 gr jus tomat selama 7 hari. Dan penelitian Rini (2016) dengan memberikan Jus Kombinasi (Jeruk, Tomat dan Pisang Ambon) didapatkan hasil bahwa terjadi penurunan tekanan darah sistolik dan diastolik pada lansia di PSTW Teratai Palembang dengan diberikan jus berupa 100 gr pisang ambon, 150 gr tomat, 150 gr jeruk selama 6 hari.

Peran kalium telah banyak diteliti dalam kaitannya dengan regulasi tekanan darah. Mekanisme bagaimana kalium dapat menurunkan tekanan darah adalah kalium dapat menurunkan tekanan darah dengan vasodilatasi sehingga menyebabkan penurunan retensi perifer total dan meningkatkan output jantung, kalium dapat menurunkan tekanan darah dengan berkhasiat sebagai diuretika, kalium dapat mengubah aktivitas sistem reninangiotensin, kalium dapat mengatur saraf perifer dan sentral yang mempengaruhi tekanan darah. Kalium (potassium) merupakan ion utama didalam cairan intraseluler (Astawan, 2002 dalam Imammudin, 2016).

Selain zat gizi kalium, kandungan yang berperan adalah serat. Mekanisme serat untuk menurunkan tekanan darah berkaitan dengan asam empedu. Serat pangan mampu mengurangi kadar kolesterol yang bersirkulasi dalam plasma darah dengan cara mengikat garam empedu,mencegah penyerapan kolesterol didalam usus dan meningkatkan pengeluaran asam empedu lewat feses yang dapat meningkatkan konversi kolesterol plasma menjadi asam empedu dan mengakibatkkan menurunnya tekanan darah (Lestari, dkk. 2012 dalam Kholifah, dkk. 2014).

\section{KESIMPULAN}

Ada pengaruh pemberian puding tomat pisang ambon terhadap penurunan tekanan darah sistolik namun tidak ada pengaruh terhadap penurunan tekanan darah diastolik.

\section{SARAN}

Hasil penelitian ini dapat menjadi pertimbangan sebagai salah satu metode terapi non farmakologis dalam menurunkan tekanan darah yang dapat diterapkan secara mandiri oleh lansia hipertensi di wilayah kerja Puskesmas Babakan, Kota Mataram.

\section{DAFTAR PUSTAKA}

Alini. (2015). Pengaruh Terapi Herbal Air Kelapa Muda Terhadap Penurunan Tekanan Darah Pada Penderita Hipertensi di Desa Tambahrejo Kecamatan Bandar Kabupaten Batang. Jurnal Keperawatan

STIKes Tuanku Tambusai Riau. Fahriza, T., Suhadi, \& Maryati. (2014). Pengaruh Terapi Herbal Air Kelapa Muda Terhadap Penurunan Tekanan Darah Pada Penderita Hipertensi di Desa Tambahrejo Kecamatan Bandar Kabupaten Batang. Jurnal Ilmu Keperawatan Dan Kebidanan (JIKK).

Hananta, Putu Y. dan L.M Freltag Harry, 2011.Deteksi Dini \& Pencegahan 7 Penyakit Penyebab Mati Muda. Media Pressindo. Yogyakarta.

Handayani, Y. N. \& Sartika, R. A. (2013). Hipertensi pada pekerja perusahaan migas X di Kalimantan Timur, Indonesia.

Imammudin, W. P. (2016). Hubungan Antara Asupan Kalium dengan Tekanan Darah pada Lanjut Usia di Posyandu Lansia Ngudi Waras di Desa Blulukan, Kecamatan Colomadu, Karanganyar, Jawa Tengah . Universitas Muhammadiyah Surakarta.

Irza, Syukraini. 2009. Analisis Faktor Risiko Hipertensi pada Masyarakat Nagari Bungo Tanjung, Sumatra Barat. Universitas Sumatra Utara.

Kementerian Kesehatan Republik Indonesia. 2013. Riset Kesehatan Dasar 2013. Badan Penelitian dan Pengembangan Kesehatan. Jakarta. 
Kholifah, F, Nur, dkk. 2014. Serat dan Status Gizi Kaitannya dengan Tekanan Darah pada Pasien Hipertensi Rawat Inap di Rumah Sakit Umum Daerah Tugurejo Semarang. Program Studi D III Gizi Fakultas Ilmu Keperawatan dan Kesehatan. Universitas Muhammadiyah Semarang.

Lara, M. 2013. Hubungan Gaya Hidup Dan Pola Makan Dengan Tekanan Darah Pasien Hipertensi Rawat Jalan Di RSUD Kota Mataram. Karya Tulis Ilmiah. Politeknik Kesehatan Kemenkes Mataram.

Mahmudah, dkk. 2015. Hubungan Gaya Hidup dan Pola Makan dengan Kejadian Hipertensi pada Lansia di Kelurahan Sawangan Baru. Biomedika, Volume 7 Nomor 2, Agustus 2015.

Muliyati, H, Syam, A, Sirajuddin, S. 2011. Hubungan Pola Konsumsi Natrium dan Kalium serta Aktifitas Fisik dengan Kejadian Hipertensi pada Pasien Rawat Jalan di RSUP DR. Wahidin Sudirohusodo Makassar. Media Gizi Masyarakat Indonesia, vol.1, no.1, Agustus 2011.

Novitaningtyas, T. 2014. Hubungan Karakteristik (Umur, Jenis Kelamin, Tingkat Pendidikan) Dan Aktivitas Fisik Dengan Tekanan Darah Pada Lansia Di Kelurahan Makamhaji Kecamatan Kartasura Kabupaten Sukoharjo. Skripsi. Universitas Muhammadiyah Surakarta.

Nurjanah, Suptijah, P., \& Rani, L. (2007). Pembuatan tepung puding instan karaginan. Buletin Teknologi Hasil Perikanan, $X$.

Prayitno, N. \& Anggara, F. H. (2012). Faktorfaktor yang berhubungan dengan tekanan darah di Puskesmas Telaga Murni, Cikarang Barat tahun 2012.

Perhimpunan Dokter Spesialis Kardiovaskular Indonesia, 2015. Pedoman Tatalaksana Hipertensi Pada Penyakit Kardiovaskular.

Raihan, L. Najmi, Erwin, \& Dewi. A P. Faktor-faktor Yang Berhubungan Dengan Kejadian Hipertensi Primer pada Masyarakat di Wilayah Kerja Puskesmas Rumbai Pesisir. JOM PSIK Vol.1 No.2 Oktober 2014.Yang Berhubungan Dengan Kejadian Hipertensi Primer pada Masyarakat di Wilayah Kerja Puskesmas Rumbai Pesisir. JOM PSIK Vol.1 No.2 Oktober 2014.

Rini, P. S. (2016). Pengaruh Ramuan Jus ( Tomat, Jeruk, Pisang Ambon Dan Kombinasi) Terhadap Tekanan Darah pada LAnsia di PSTW Teratai Palembang.

Riyadi A, 2006. Asupan Gizi dan Status Gizi Sebagai Faktor Risiko Hipertensi Esensial Pada Lansia di Puskesmas Curup dan Perumnas Kabupaten Rejang Lebong Propinsi Bengkulu. Tesis Ilmu kesehatan Masyarakat Universitas Gadjah mada, Yogyakarta.

Seke, P. A., Bidjuni, H. J., \& Lolong, J. (2016). Hubungan Kejadian Stres Dengan Penyakit Hipertensi Pada Lansia Di Balai Penyantunan Lanjut Usia Senjah Cerah Kecamatan Mapanget Kota Manado. E-Journal Keperawatan $(e-K p), 4$.

Suhadak, Aris, A., \& Priyoto. 2011. Pengaruh Pemberian Teh Rosella terhadap penurunan Tekanan Darah Tinggi pada Lansia di Desa Windu Kecamatan Karangbinangun Lamongan. BPPM. Stikes Muhammadiyah Lamongan.

Susanti, M, Rahayu. 2017. Hubungan Asupan Natrium dan Kalium dengan Tekanan Darah pada Lansia di Kelurahan Pajang. Naskah Publikasi. Fakultas Ilmu Kesehatan. Universitas Muhammadiyah Surakarta.

Widyaningrum, A.T. 2014. Hubungan Asupan Natrium, Kalium, Magnesium dan Status Gizi dengan Tekanan Darah pada Lansia di Kelurahan Makamhaji Kecamatan Kartasura. Naskah Publikasi. Program Studi Gizi. Faultas Ilmu Kesehatan. Universitas Muhammadiyah Surakarta. 